\section{Identity lost? The personal impact of brand journalism}

2017, Vol. 18(2) 195-210

(C) The Author(s) 2015

Reprints and permissions: sagepub.co.uk/journalsPermissions.nav DOI: I0.1 I77/|4648849|56088|6 journals.sagepub.com/home/jou

@SAGE

\section{Avery E Holton}

The University of Utah, USA

\section{Logan Molyneux}

Temple University, USA

\begin{abstract}
Researchers have explored the role of organizational and personal branding in journalism, paying particular attention to digital media and social network sites. While these studies have observed a rise in the incorporation of branding practices among journalists, they have largely avoided questions about the implications such shifts in practice may have on the personal identities of journalists. This study addresses that gap, drawing on interviews with $4 \mathrm{I}$ reporters and editors from US newspapers. The findings suggest that as reporters incorporate branding into their routines, they may feel as though they are sacrificing the ability to simultaneously maintain a personal identity online. For their part, editors seem to sympathize with journalists' loss of personal identity but defer to organizational policies.
\end{abstract}

\title{
Keywords
}

Branding, brand journalism, identity, normalization

\section{Introduction}

Businesses small and large work to enhance their brand images through a variety of traditional and not-so-traditional means, including deep investments in advertising and novel approaches to audience engagement through social network sites. That enhancement has become increasingly complicated with the uptake of social media, which has upset the

\section{Corresponding author:}

Avery E Holton, Department of Communication, The University of Utah, 255 Central Campus Drive, Salt Lake City, UT 84I I2, USA.

Email: averyholton@utah.edu 
relational balance between businesses, their competitors, and the consumers whose attention they seek (Nitins and Burgess, 2014). The same holds true for the news media, which are experimenting with social media in various ways. Just like brands such as Nike and McDonalds wrestle with how to brand themselves to an audience that increasingly demands stronger engagement through social media (Nitins and Burgess, 2014), so too do news organizations search for ways to enhance their branding efforts.

This pursuit comes at a time when the foundations of journalism practice are undergoing drastic transformations. A number of new digital communication tools, especially social media, have given rise to a news and information environment in which news consumers exchange information with news producers and have increasing opportunities to participate in the newsgathering and reporting process. This engaged audience is exerting pressure on traditional journalistic norms and practices (Bruns, 2012; Hermida, 2014; Holton et al., 2013). As a result, journalists have evolved quickly, placing less focus on some traditional tenets of journalism and incorporating new practices, including the injection of humor, opinion, and branding into their news content (Molyneux, 2014; Schultz and Sheffer, 2012). Many of these changes have come as part of what Lewis (2012) calls as an 'ethic of participation' wherein journalists feel a certain level of responsibility to engage audiences on deeper, more sustained levels. Journalists have been hesitant to fully embrace branding even while recognizing its importance to the sustainability of news organizations and its necessity for creating individual identities as journalists (Molyneux and Holton, 2015; Schultz and Sheffer, 2012). More specifically, reporters have said they aren't sure how to balance professional and personal identities on social media or even what their employers expect, and this has led them to approach branding experimentation with caution (Molyneux and Holton, 2015). Their uncertainty and trepidation are understandable given the sometimes stiff penalties for getting it wrong - a number of journalists have been fired for social media missteps (Farhi, 2014). Using a series of depth interviews with 41 journalists, including reporters and editors, this study investigates the role of branding in shaping journalists' identities, considering its potential impacts on their personal and professional lives, and the way their editors view these changes.

\section{Identity and journalism}

One's identity is formed by developing a distinct personality, defining personal characteristics by which one may be recognized as a unique entity. This identity is commonly seen as dependent on one's social situation. Goffman (1959) suggested that people perform aspects of themselves for an audience, with both performer and audience contributing to the construction of the performer's identity. Without an audience, there is no need for a performance and no need for an identity to be created and defined. Erikson also suggested that one's identity does not exist until it has been recognized by others, emphasizing the importance of one's interactions with and placement in society in defining an identity (Erikson, 1968). Identity, then, is developed only when it must be shared.

Sharing a personal identity with many others is made easier by social media, but the system also brings some inherent complications. One's 'audience' on social network sites is neither clearly defined nor homogeneous. Instead, it might include personal 
acquaintances from many different social groups (former schools, church, etc.) along with co-workers and professional contacts. As a result, it has been suggested that social media users resort to imagining an audience when formulating social media messages (Marwick and boyd, 2010). How this audience is imagined, then, influences the content of people's postings. Social media (among other networked technologies) allow connections with a greater diversity of audiences than would normally be encountered in everyday life (Papacharissi, 2010), thereby enabling users to voice multiple aspects of their personality and develop them further. Essentially, a person's identity is made up of multiple sub-identities tailored to each social group a person interacts with. This multiplicity, however, creates challenges to defining oneself consistently (Davis, 2011).

A professional identity might be developed in order to interface with those a person meets on the job, including co-workers and clients, and would be determined by different factors and have different goals from a personal identity. Still the two are not completely separable, as people also may develop both personal and professional relationships with co-workers, for instance. Here, we use 'professional' to refer to work-related aspects of identity and 'personal' to refer to non-work-related aspects. When considering professional identities, one's level of autonomy is key in determining identity development. A drone that does nothing but follow orders is indistinguishable from his fellow workers. On the other hand, a professional given charge over a certain area of work and the autonomy to direct his own work within that area begins to develop a professional identity separate from his co-workers and supervisors. For instance, a study of English schoolteachers found that imposing a prescribed curriculum negatively affected the teachers' professional identity (Siraj-Blatchford, 1993). Autonomy in a journalistic sense has often meant independence from external influences (Deuze, 2005), but journalists frequently come under pressure from the organizations they work for as well. Having a boss is obviously part of working for hire, but workers' professional identity development depends in part on their level of autonomy.

Journalists have not traditionally needed to develop any kind of audience-facing identity. In fact, doing so in one's news stories (which, before the digital age, were journalists' main direct contact with their audience) would have been in violation of the objectivity norm, which calls for journalists to set aside most aspects of one's personality and opinions and report only the facts. Furthermore, the news organization has traditionally been the center of most journalism activity. Journalists have tended to separate themselves from other writers primarily by their employment in a news organization (Singer, 2005). Of course, journalists have always had bylines, but highly recognized names like Dan Rather or Barbara Walters are the exception rather than the rule. In contrast, most journalists work in relative anonymity, with some widely read publications including The Economist and (formerly) Time choosing to print stories without bylines at all.

This is not to say that journalists have no identity; rather, this identity was not often shared with news audiences. Like anyone else, journalists develop their personal identities within whatever social contexts they inhabit. They also develop professional identities by carving out beats and adhering to certain values that distinguish them from other professionals (Deuze, 2005). Observers argue that the nature of the journalist-audience relationship is changing to include two-way communication, feedback, and social 
interactions (Bolin, 2012; Domingo, 2011; Rosen, 2006). This, accelerated by the spread of social media, has created opportunities for journalists to build individual brands.

Two other trends may also influence how journalists share their identities online. The first is an embrace of a new norm of transparency, perhaps spurred by a culture of openness on the Internet (Hellmueller et al., 2012; Phillips, 2010). A journalist seeking transparency allows the audience to see both professional and personal identities in an effort to appear more authentic and trustworthy. This trend is accelerated by social media use, wherein personal interactions are key. An emphasis on transparency thus challenges the objectivity norm and gives rise to opportunities for journalists to promote themselves and their content.

Another trend influencing journalists' sharing of identity comes from outside the profession itself. The news industry as a whole and print enterprises especially are experiencing an economic crisis (Pew Research Center, 2014). This has forced reductions in staff at many media organizations and placed in jeopardy many remaining jobs. This climate has induced many journalists to think of themselves as expendable in their jobs and to develop strategies to demonstrate their expertise and value to both employers and audiences (e.g. individual branding). In this process, some control is wrested from the organizations themselves and is placed in the hands of individual journalists, giving them more autonomy. This demonstration of value, identity, and autonomy is a core aspect of brand journalism.

\section{Branding and brand journalism}

Branding is a term more commonly used in advertising and marketing, where it generally is taken to mean differentiating a product from others on the market and making claims about its quality and origin. Branding is a process of forming relationships with potential buyers, often via media as well as other communication techniques (Coomber, 2002). The goal of these efforts is to create loyalty, an economic and emotional attachment in consumers that drives a desire to buy and/or share the product (Allen and Meyer, 1990; Nitins and Burgess, 2014). Ideally, the consumer's attachment is to a brand's identity, which is typically represented by a set of claims and characteristics that may go beyond the product itself. This identity is developed using logos, slogans, commercial advertisements, and testimonials or other design elements meant to appeal to a target audience (Williams, 2012). These claims often emphasize what unique value a product might offer consumers compared with competitors (Murphy, 1987). But branding is not a single appeal; it is a collection of efforts over time meant to manage and maintain a brand image or brand identity.

Social media and an always-on digital culture have made ongoing branding efforts even more necessary (Turri et al., 2013). That is not to say this is entirely a burden. In fact, some individuals and organizations value social media's ability to facilitate collaboration and co-creation of brand content, which allows a more personal connection between consumers and the brand (Turri et al., 2013). Such personal connections promote brand intimacy, an important step in helping consumers personalize a brand (Tuten and Solomon, 2012) and indeed to personalizing the news (Hermida, 2014; Meraz and Papacharissi, 2013). 
In the news business, these concepts have traditionally applied only to news organizations. It was the organization that was most recognizable and that had a reputation to protect. Therefore, it was the focus of most branding activities, and most of these activities were handled at the organizational level as well. Editorial staffers have traditionally been separated from advertising and marketing teams working to brand the news organization, and most reporters were not obliged to participate in these branding efforts. This situation is now changing as journalism norms adjust to internal and external forces. Branding has developed unevenly across different types of journalism and is practiced in a number of different ways, ranging from the promotion of individual content to the sharing of an organization's mission (Molyneux and Holton, 2015). As such, there is no unified definition of brand journalism, although most journalists are aware of the practice.

Journalists' primary audience for these branding efforts has typically been those who consume and share their news content. Journalists' work eventually ends up in front of an audience, and journalists are beginning to realize the necessity of branding themselves for their audience, especially using social media (Carrera Álvarez et al., 2012; Dickinson, 2011). The relationship between journalists and news consumers is not regularly strengthened by any financial transactions given that most liberal-model journalism is funded by advertising rather than subscriptions. As such, branding efforts may at first appear to be only an effort to gain exposure for one's work. But developing a relationship with the audience is also part of the value proposition individual journalists make to their employers, both present and future: I can bring you this information, this writing expertise, and also this group of followers who are already interested in my content.

\section{Problem statement}

Brand journalism therefore incorporates several practices that have the goal of increasing a journalist's reputation and attracting attention to oneself, one's work, and potentially one's organization. Brand journalism is the set of activities that create an identity for an individual journalist and then promote that identity by building relationships. Yet, exactly what that identity is and what impact its creation may have on journalists have not yet been explored. While some research has explored the various ways in which journalists are incorporating branding into their routines (Molyneux and Holton, 2015), none have yet examined how journalists perceive such changes and how their personal identities might be evolving because of those changes.

This study seeks to address that research gap, asking how journalists see their personal and professional lives changing in light of brand journalism that occurs at the organizational (i.e. branding an organization) and individual levels (i.e. branding one's self). As Revers (2014) noted, media research exploring changes in journalism practice has placed a significant emphasis on surveying journalists and other news producers but have largely ignored more in-depth approaches that are necessary for exploration and understanding of those changes. In order to begin peeling back the intricate connections between personal identity and brand journalism, this study sought interviews with those journalists - both reporters and editors - who may be most likely to incorporate change into their professional practice ahead of other news producers, asking them how, if at all, 
the inclusion of individual and/or organizational branding in their daily routine has impacted their personal and professional identities.

\section{Method}

Given that brand journalism is a relatively new phenomenon in journalism practice, this study sought journalists who have been identified for incorporating changes into their routines ahead of and with more flexibility than other journalists. Some studies have suggested that journalists covering issues of health and science tend to be more adaptive to such changes (Holcomb et al., 2011; Secko et al., 2013); thus, this study relied on semistructured interviews with those individuals. Qualitative approaches to journalism research not only help to reveal perceptions and concerns among journalists (Robinson, 2011) but also provide flexible means to approach unexplored or underdeveloped areas of interest (Amend and Secko, 2012; Brennen, 2013; Revers, 2014). Additionally, interviews that are flexible and semi-structured are less restrictive than close-ended methods and often provide opportunities for richer and potentially unanticipated responses (Brennen, 2013). An appropriate and available group of individuals must first be identified for such analysis to take place (Konieczna, 2013).

Reporters and editors with specialties in health and science were sought through the Association of Health Care Journalists (AHCJ). With more than 1100 individual members, the AHCJ provides the most extensive collection of US reporters and editors covering health and other issues of medical and scientific natures. For this study, AHCJ agreed to contact its members through an e-mail, informing them of the study and how to contact the primary researcher for participation. Members were specifically invited to take part in interviews concerning their professional roles as journalists and their perceptions of branding in journalism, both organizational and individual. In all, 41 journalists agreed to participate in interviews that were conducted by the primary researcher over the phone or through Skype. All interviews took place in April and May 2013, and as with successful semi-structured interviews, participants were encouraged to build upon their answers and to provide as much information as they wished. The primary researcher engaged in follow-up questions when appropriate.

The primary researcher transcribed all interviews, noting along the way emergent patterns in responses as suggested by Strauss and Corbin (1998) and Birks and Mills (2011). This allowed for an organic development of categorizations that either withered or grew with each interview, depending on their occurrence. As encouraged by other scholars who have undertaken semi-structured interviews, this process of categorization was carried out until no further categorizations could be developed from the transcribed interviews (see Charmaz, 2006; Holloway, 2008; Oktay, 2012; Strauss and Corbin, 1998).

\section{Results}

Participants represented a wide range of backgrounds, although all considered themselves to be professional reporters or editors. Nearly all of the participants had obtained at least a 4-year college degree, and most had been working as journalists for at least 2 years. A notable contingent of participants reported working in journalism for more 
than a decade, representing a variety of textual media including local, regional, and national newspapers and/or digital-first news media. Among those editors interviewed, the majority reported serving as section, area, or managing editors.

When questioned about their branding practices, participants reported a spike in both individual and organizational branding beginning several years ago. While reporters noted freedom in individual branding early on, they overwhelmingly saw it shifting to an organizational function wherein they were asked to make changes, some subtle and some significant, to the ways in which they presented themselves and their content on social media platforms. Those changes included adding organization names, logos, and/or links to their social media bios; providing fewer links to stories published outside of the organization and more to those that directed back to the organization; publicizing events, promotions, and partnerships that might cast the organization in a positive light; and working with the organization on more engagement through hashtag conversations on Twitter and tutorials and other forums on Facebook and LinkedIn.

Participants reported an interest in helping improve the image of their media organizations, noting they were hesitant to do so at the risk of altering their individual brand or becoming what one reporter called 'a wash of advertising mess mixed in with strong news content that does nothing but push audiences away'. They sought ways to balance their individual and organizational identities online, saying that such endeavors were increasingly difficult as editors and publishers paid more attention to their social media activity. Nearly, all participants reported shifting from individual to organizational branding on Twitter, Facebook, and LinkedIn, while some said they still maintain control on more private-facing platforms such as Instagram and Snapchat. Yet, when discussing the latter two, participants talked more in terms of relational uses (e.g. posting family photos, connecting with new friends, sharing quick bits of gossip with friends and family) than they did for branding.

\section{Branding broadly}

Journalists said their use of social media platforms began as a way to exchange news and information with other users all while presenting oneself and one's interests through content selection, biographical information and images, and interactions with audiences. On Twitter, they were able to pepper their bios with information that identified their specialties as well as their interests outside of journalism so long as they made it clear, as one journalist pointed out, 'that information here is my opinion and does not represent $\mathrm{X}$ organization'. They were also able to share content rather freely, passing along links to outside news organizations that they found interesting or relevant to their audiences. On Facebook, many said they kept private profiles and let their organizations instead serve as megaphones of information. They could move in and out of those spaces with relative ease, taking care to abide by content and engagement guidelines set forth by their organizations. On LinkedIn and other more professionally focused platforms, they presented only their biographical information alongside resumes, occasionally chatting with colleagues or sifting through tips of the trade. Collectively, journalists said they were able to cast themselves as they saw fit, selectively choosing the persona the public saw. 
Feeling anxious about industry-wide cutbacks, and seeing the opportunities other journalists had to create their own professional identities, the journalists interviewed here said they began evaluating ways to enhance their identities through their social media presentations (i.e. bios, landing pages), the content they shared and produced, and the ways in which they engaged news consumers. At the same time, many reporters said they felt as though social media gave them a chance to distance themselves from wire reporters or other reporters who were assigned health and science stories with little or no background in those areas. By crafting strong bios, sharing links to information their audiences might value, being transparent with their sources, and engaging audiences whenever possible, they were able to craft themselves as 'true journalistic experts' in their fields.

Specific to branding, reporters said they were becoming more involved in engaging users through what several reporters called 'audience maintenance'. This included rich levels of conversation with social media users alongside surface interactions such as liking a user's post, favoriting a user's tweet, or promoting a user's expertise on LinkedIn. Again, while there were organizational guidelines for reporters and editors in some cases, expectations of branding drove participants to these and other forms of maintenance, which were relatively new experiences for those interviewed.

\section{Organizational control}

'What began as an opportunity to say, "Hey, this is who I am. Come check me out", as one reporter noted, 'has quickly deteriorated into a demand to say, "This is who I work for. Go check them out"'. This sentiment was present in nearly every reporter interviewed. Things began to change several years ago when some news organizations tightened the reins on social media content and engagement. As one reporter puts it, 'There were some mistakes made by a handful of reporters out there. Some posted misinformation. Some posted opinions that didn't quite fit with their bosses'. Some went after their audiences. That's when things started to change across the board'. Some news organizations began passing out social media guidelines or requiring their employees to attend training sessions, according to some of the participants. Others sent out blanket e-mails, tempering reminders about company policies with encouragement for engaging audiences. They said the pressure came on rather strongly.

What was initially optimism in a new form of audience engagement was squelched to a degree by the insertion of organizational pressures. Some reporters noted continued freedoms to navigate their own individual brands, but the majority said they had been part of discussions with their editors, other reporters, and in some cases publishers that placed the organization, not the individual, at the center of branding efforts. Beyond traditional branding efforts on the part of organizations (e.g. television advertisements, community sponsorships, corporate partnerships), organizations began asking, or requiring, reporters to cease some individual branding exercises while taking part in other more organizationally focused efforts.

For many reporters, this began with subtle suggestions from their editors or organizations to tone down inclusions of their personal lives (i.e. remove family photos, scale back posts related to daily routines). Those suggestions then turned into stronger demands 
to avoid promoting the work of any reporters or news organizations other than their own, to increase the number of links back to the organization, to 'talk up' the organization even in casual social media conversations, and to reshape their personal and biographical information to fit the organizational mold. 'I spend so much time trying to put the best product out there that I can', one journalist lamented, 'only to become some advertising "schlub" who's become known, if I can even say that, more for his reporting on the intricacies of human genomes than he has for the human beings he goes to home every night'.

Many reporters complained of general demands for organizational branding rather than specific guidelines, but others said they were pressured to incorporate certain typologies of branding into their everyday routines. Those included linking to other content and reporters within their organization; casting the organization in a positive light whenever possible; including the name of the organization in any social media bios; using headshots provided by the organization; in some cases using hashtags and keywords created by or for the organization; taking part in specialized chats in Twitter, Facebook, and on LinkedIn guided or moderated by upper management; and devoting more time to finding novel ways of engaging audiences with the brand, rather than themselves. 'Sometimes the details were so minute and, well, detailed', one reporter said:

Other times, I really had no idea what they meant. If I was supposed to talk myself up less and the company more, but I was also supposed to find better ways to get the company name engaged on Twitter, then what was I really supposed to be doing?

\section{Identity lost}

As organizational pressures (although not necessarily specific mandates) grew, many reported a concerning loss of personal identity through social media channels, saying that they have supplanted much of their personal information, content, and conversations with more professionally driven, organizationally aligned messages. One reporter called this process 'skating on ice with Ginsu knives', saying that journalists were being forced to reinvent themselves so much so quickly that "not only are some of our practices changing for better or for worse, but we're changing too. As journalists, we're starting to turn into ghosts'. With that, the journalist proposed what many others interviewed here did as well: a potential loss of personal identity in light of branding, the very mechanism that many said initially held such promise for them to promote themselves.

In nearly every instance, participants said they had altered the appearance of their social media landing pages, selecting photos, and text that matched the brand their organizations called for. In some cases, reporters used text and links provided by their organizations. In others, attempts were made to keep some sense of personal identity in biographical information through quirky notes (e.g. 'Reporter of curiosity. Pursuer of truths. Diver of reefs. Boy among men'; 'Medical innovation reporter by day, whiskey pourer by night'), but those were often met with either critical responses from upper management or with fears that if management were to see them, the repercussions might be severe.

While some reporters said they balanced their personal lives with their professional lives by creating separate social media accounts or relying on less-public platforms (e.g. 
Instagram, Snapchat) for personal content, the majority felt as though they shouldn't have to represent themselves so dichotomously. 'If all the facts show that people want to know more about us, what we think, what we do, how we act, then why strip that away from us?' asked one journalist. Others simply said they had given up on trying to provide glimpses of themselves alongside their work, instead using social media only as it related to their professional practice and nothing more. While a relative few said that organizations specifically requested less personal information in their social media interactions, most said they felt as though that was expected. Organizations, participants felt, were more interested in the work they produced and their ability to promote the organization itself than they were in hearing about the daily lives of their employees. Reporters said that they felt expected to be 'team players' and 'good confederates', even if that meant sacrificing themselves along the way.

Reporters said they felt as though they had morphed from individuals working as journalists for a news organization into organizational representatives who also happened to produce journalism and frequently engage the public in conversation. Although their freelancer peers were actively practicing individual branding, and although they readily acknowledged the public's interest in their day-to-day routines and their personal lives, reporters said they placed more emphasis on branding themselves as professionals to appease their organizations. No longer were they able to offer a mixed approach to the personal and professional on social media, but were instead focusing nearly all of their time on the latter. At a time when the news media has become 'ambient' or 'always on' (Hermida, 2010, 2014), these journalists said they felt like 'ambient professionals' who could never fully escape their identity as journalists.

If they could not be themselves on social media, which again is always on, then where could they be? This question arose time and again, often correlating with expressions of anxiety and stress. Some reporters reported expressing their concerns to upper management, and nearly all said they had talked with their editor(s) on at least one occasion about balancing their personal and professional identities, especially through social media.

\section{Concerns and consequences}

The abrupt change in policy caused an added level of anxiety for many participants. They said the combination of pressure from their peers and organization, along with an incomplete sense of what exactly branding was and what was expected, could be a barometer for the health of their organizations, if not the state of the news media.

\footnotetext{
'You might think that this is just journalists being journalists, that we bitch and moan about every new thing we have to do', said one long-time reporter, 'but that's just not the case. With blogs and then social media, there was a little gap of experimentation before we started to get things more or less in line. The views and goals were pretty clear. With [branding], all we know is that we're supposed to be doing our job, doing it well, and pitching whatever [the organization] wants to sell this week.'
}

That sentiment has kept some reporters and editors from fully aligning their branding practices with their organizations, demonstrating a continued tension between the two. 
Despite continued, and in many cases growing, internal pressures, some participants have remained resistant to changes that have the potential to alter their journalistic routines while stripping away some layers of their personal and professional identities.

Reporters were further concerned about the implications their organizational branding work could have on audience trust. They reported working tirelessly to build trust through transparency and information extensions (i.e. providing links, following up on inquiries from audiences) and worried that mixing advertising and marketing alongside their news content could hamper those efforts. As one reporter said:

We're people, too, and I think my readers get that. They get that I'll promote my stuff and the stuff I like with the news I report. That's normal and natural, but to suddenly throw something in there that says my organization is the leading or only source for health care coverage? That has to raise some eyebrows.

Reporters took these concerns about identity and loss of values to their editors. Indeed, the majority of editors interviewed said they had repeatedly addressed those and similar concerns through multiple channels (i.e. in person, via e-mail and phone). These editors largely sympathized with their reporters, emphasizing the difficult level at which journalists are now expected to navigate the personal and professional sides of their lives. 'They once were bylines behind a story', one editor noted, 'and now they are expected to be part of the process of that story. People want to understand where the journalist fits into the story, and how that story affected that journalist's life'.

Despite such sympathies, editors also reported grappling with the tensions wrought by organizational branding mandates, saying that while they saw a definite need to 'allow our people a chance to break away from the burdens of the media cycle', they nonetheless had to pass along suggestions, rules, and regulations from upper management. Editors reported feeling very little control when it came to branding, especially since they were neither developing branding guidelines nor putting them to use in such public fashions as their reporters. Few said that they monitored all of their reporters' social media activities, but that their organizations frequently made examples out of individuals who were not falling in line. For instance, one editor recalled a time when a younger reporter failed to incorporate his organization's homepage link into his Twitter bio:

You would have thought the Seven Horsemen had settled into that board room. Luckily [the reporter] wasn't there himself, or I'm sure he would have been chased out of here for good. [Upper management] had made a game of finding little holes or gaps in our efforts, so when they saw he wasn't complying, they unleashed hell on me and some of the other editors. To them, we weren't taking our jobs seriously. To us, they were forgetting what journalism was actually about.

Other editors shared similar stories, often offering interactions with freelance reporters as a stark contrast. Editors took note of freelancers' ability to develop personal brands, bemoaning the fact with upper management that their employees could not do the same, not because it reflected poorly on themselves or on the organization but rather because they noticed much more positive interactions between freelance reporters and their audiences. 
Editors affirmed that freelance reporters could serve as de facto intrapreneurs, testing uncharted waters of new journalistic practices such as branding with little or no consequence to the news organization. At the same time, their successes can inform news organizations as to what does and does not translate well into practice, according to the editors interviewed here. Yet, freelance reporters and reporters employed full-time by news organizations operate under much different principles and guidelines. Expectations of branding, for example, are at a minimum for freelance reporters despite their efforts, while they continue to rise for reporters employed by news organizations.

In summary, expectations for the inclusion of organizational branding have surpassed sympathies toward the inclusion of personal identity on social media, a change seemingly acknowledged by the majority of reporters and editors in this study. While journalists collectively wrestle with evolving journalism practices that demand more transparent forms of audience engagement, they do so while attempting to satisfy their organizations. Those organizations, in turn, place more value on reporters as organizational branders and professionals, limiting reporters' ability to express personal identity online. For their part, editors are sympathetic to the changes branding has brought onto reporters, but at the same time are hamstrung by the policies and expectations of the news organizations they serve.

\section{Discussion}

The interviews presented here suggest that reporters are feeling pressure to participate in branding activities from at least three sources - their supervisors, their colleagues, and the public - and that they feel they must respond to these pressures roughly in that order. Even if reporters originally created personal profiles on social media, their activity there is increasingly focused on developing professional identities rather than personal ones. Both reporters and their editors (although to a lesser extent) expressed concerns about focusing on professional identities to the exclusion of reporters' online personal identities. Previous research has identified journalistic branding as an emerging practice in which journalists sense uncertainty and tension between organizational and individual forces (Molyneux and Holton, 2015), and the results presented here suggest that reporters are being pushed to perform professionally as they brand both themselves and their organizations.

To reiterate, reporters promote themselves on social media while also promoting the organizations they work for, but the key contribution of the results presented here is that both types of promotion are professionally focused rather than personally focused. Reporters feel pressure to stake a claim on their beat, develop a presence as an expert in their profession and area of coverage, and act as a representative of the news organization at all times. This leaves little room for aspects of personal identity such as family, faith, or friendship to be shared online. This particular aspect of detachment from self in order to provide an objective public service is nothing new in journalism. In fact, it is the subject of backlash from many commentators, not least of whom is Jay Rosen, who calls this detachment 'the view from nowhere' and decries it as a bid for authority where none has been earned (Rosen, 2010). A focus on transparency is meant at least in part to address this critique, but among reporters, transparency appears to apply only to professional activities and does not extend to their personal lives. 
In cases where organizational and individual forces collide, the organization often wins. This point is reinforced whenever a journalist is fired or disciplined because of something they have posted on social media, which is not uncommon (Farhi, 2014). In the interviews presented here, journalists (especially reporters, but also their editors) expressed uncertainty about what is acceptable practice when using social media in general and specifically when branding oneself or one's organization. A potential consequence of not knowing what crosses the line is that journalists play it safe, presenting only an objective, professional identity.

An important question is how this focus on professional identity and suppression of personal identity might affect reporters and editors, their organizations, and their audiences. Many of the participants interviewed here indicated that, if they are expected to present a professional face online all the time, stress was a major concern. Of course, the branding activities at the center of this study take place primarily on social media, and journalists are not necessarily being asked to be at work longer. They are, however, being asked to be aware of work at all times, including reading and responding to social media posts whenever they are made and generally behaving in all settings as representatives of the organization. Reporters specifically indicated they viewed this as an added burden on top of an already long list of responsibilities.

Additionally, a focus on professional identity complicates attempts at transparency if reporters are suppressing their personal identities. To the extent that professional identity trumps the personal, reporters may seem less like people covering the news, less like concerned citizens, and more like extensions of the organization that employs them. This surrogacy risks pushing reporters back into the anonymous background, as subordinates to the organization, from which social media had given them a chance to emerge. Reporters expressed dismay at litanies of social media guidelines that restricted what they could do there and longed to 'take back their Twitter feed' or own their online presence. Journalists employed by news organizations, then, might consider incorporating some lessons from their freelance peers, who appear to be integrating personal and professional identities to some extent and with some success (Hunter, 2015; Ladendorf and Edstrom, 2012).

Social media use among journalists has by now emerged from its early stages, and while there is still experimentation all around, organizations are clearly seeking to exert some control over how the organization and its employees are perceived. The tension this creates strains an already tenuous relationship between journalist (Am I about to be laid off?) and employer (Am I losing the audience?). The interview quoted above in which a reporter was perceived to be better off as a freelancer is telling: As difficult as life is for news companies, things can only get worse if they drive away their employees. What is more, many people ignore advertising or purposely avoid it (Cho and University of Texas at Austin, 2004), meaning that an emphasis on organizational branding activities could end up driving away audience rather than securing their loyalty. Organizations themselves are facing pressures as well, of course, not the least of which is improving the bottom line, but they will have to strike a balance with regard to branding.

This study was informed by interviews with a subsection of specialty reporters and editors in health coverage and so may not represent all areas of journalism. Reporters in specialty fields such as health may actually be ahead of the adoption curve regarding branding practices because of their relatively specific coverage area. While scholars have 
noted that this particular specialty is adept at integrating new practices into their routines, future studies should examine the corpus of journalists to see how, collectively, journalists are being impacted by the incorporation of branding and what differences might exist between areas of expertise, across platforms, and among digital native journalists, as well as other variables. Furthermore, this study relied on self-reports from in-depth interviews, a research method that is sometimes subject to selective memory, filtering for social desirability, and other inaccuracies. This study minimized these limitations by conducting multiple, separate interviews and noting common themes, but other research methods including content analyses, participant observations, and ethnographies could produce additional insights. Still, this study offers insights into the emerging practice of journalistic branding and the tensions between organizations and individuals that can arise from it.

Even if journalists face many different audiences on social media, their employers expect them to face everyone with a sanitized professional identity, potentially jeopardizing attempts to be relatable and collegial with members of the public (Lewis, 2012; Schultz and Sheffer, 2012). This is often done with little guidance or regulation, especially in terms of engagement with various social and digital media platforms where journalists, reporters more specifically, in this study reported different expectations and functions. Today's journalists, many of whom will have graduated with a portfolio of social media profiles, face the prospect of choosing between their online personal identity and employment in an organization. This choice presents a paradox: if journalists choose to present too much of a personal identity, they risk punishment by their employers. If they present only a professional identity, they risk offending their audiences. For social media to remain an important part of journalism, both journalists and the organizations may need to re-evaluate how they are used for branding, promotion, and creation of identities.

\section{Funding}

The author(s) received no financial support for the research, authorship, and/or publication of this article.

\section{References}

Allen NJ and Meyer JP (1990) The measurement and antecedents of affective, continuance and normative commitment to the organization. Journal of Occupational Psychology 63(1): $1-18$.

Amend E and Secko D (2012) In the face of critique: A metasynthesis of the experiences of journalists covering health and science. Science Communication 34(2): 241-282.

Birks M and Mills J (2011) Grounded Theory: A Practical Approach. Los Angeles, CA: SAGE.

Bolin G (2012) The labour of media use: The two active audiences. Information, Communication \& Society 15(6): 796-814.

Brennen BS (2013) Qualitative Research Methods for Media Studies. New York: Routledge.

Bruns A (2012) Journalists and Twitter: How Australian news organizations adapt to a new medium. Media International Australia Incorporating Culture and Policy 144: 97-107.

Carrera Álvarez P, Sainz de Baranda Andújar C, Herrero Curiel E, et al. (2012) Journalism and social media: How Spanish journalists are using Twitter. Estudios Sobre El Mensaje Periodístico 18(1): 31-53.

Charmaz K (2006) Constructing Grounded Theory: A Practical Guide through Qualitative Analysis. London; Thousand Oaks, CA: SAGE. 
Cho CH and University of Texas at Austin (2004) Why do people avoid advertising on the internet? Journal of Advertising 33(4): 89-97.

Coomber S (2002) Branding. Oxford: Capstone Publishing.

Davis K (2011) Tensions of identity in a networked era: Young people's perspectives on the risks and rewards of online self-expression. New Media \& Society 14(4): 634-651.

Deuze M (2005) What is journalism?: Professional identity and ideology of journalists reconsidered. Journalism 6: 442-464.

Dickinson RD (2011) The use of social media in the work of local newspaper journalists. In: Paper presented at $3 r$ f future of journalism conference, Cardiff University, Cardiff, 8-9 September.

Domingo D (2011) Managing audience participation: Practices, workflows, and strategies. In: Singer JB, Hermida A, Domingo D, et al. (eds) Participatory Journalism: Guarding Open Gates at Online Newspapers. Leyden, MA: Wiley-Blackwell, pp. 76-95.

Erikson EH (1968) Identity: Youth and Crisis, 1st edn. New York: W. W. Norton.

Farhi P (2014) CNN's Diana Magnay is latest reminder that Twitter can be a journalist's worst enemy. Available at: http://www.washingtonpost.com/lifestyle/style/cnns-diana-magnay-islatest-reminder-that-twitter-can-be-a-journalists-worst-enemy/2014/07/24/c1729b70-12a911e4-8936-26932bcfd6ed_story.html (accessed 3 November 2014).

Goffman E (1959) The Presentation of Self in Everyday Life. New York: Doubleday.

Hellmueller L, Vos TP and Poepsel MA (2012) Shifting journalistic capital? Journalism Studies 14: $287-304$.

Hermida A (2010) From TV to Twitter: How ambient news became ambient journalism. SSRN eLibrary. Available at: http://papers.ssrn.com/sol3/papers.cfm?abstract_id=1732603

Hermida A (2014) Twitter as an ambient news network. In: Weller K, Bruns A, Burgess J and et al. (eds) Twitter and Society. New York: Peter Lang, pp. 359-372.

Holcomb J, Gross, K, and Mitchell, A (2011) How mainstream media outlets use Twitter: Content analysis shows an evolving relationship. Pew Research Center's Project for Excellence in Journalism. Available at: http://www.journalism.org/analysis_report/how_mainstream_media_ outlets_use_twitter

Holloway I (2008) Z-Z of Qualitative Research in Healthcare, 2nd edn. Oxford: Blackwell.

Holton AE, Coddington M and Gil de Zuniga H (2013) Whose news? Whose values? Citizen journalism and journalistic values through the lens of content creators and consumers. Journalism Practice 7(6): 720-737.

Hunter A (2015) Crowdfunding independent and freelance journalism: Negotiating journalistic norms of autonomy and objectivity. New Media \& Society 17(2): 272-288.

Konieczna M (2013) Do old norms have a place in new media? A case study of the nonprofit MinnPost. Journalism Practice 8: 49-64.

Ladendorf M and Edstrom M (2012) Freelance journalists as flexible workforce in media industries. Journalism Practice 6(3): 1-11.

Lewis SC (2012) The tension between professional control and open participation: Journalism and its boundaries. Information, Communication \& Society 15(6): 836-866.

Marwick AE and boyd D (2010) I tweet honestly, I tweet passionately: Twitter users, context collapse, and the imagined audience. New Media \& Society 13(1): 114-133.

Meraz S and Papacharissi Z (2013) Networked gatekeeping and networked framing on \#Egypt. International Journal of the Press/Politics 18(2): 138-166.

Molyneux L (2014) What journalists retweet: Opinion, humor and branding on Twitter. Journalism: Theory, Practice and Criticism. Available at: http://jou.sagepub.com/content/early/2014/09/2 5/1464884914550135.full

Molyneux L and Holton AE (2015) Branding (health) journalism: Perceptions, practices, and emerging norms. Digital Journalism 3(2): 225-242. 
Murphy JM (1987) Branding: A Key Marketing Tool. Princeton, NJ: McGraw-Hill Companies.

Nitins T and Burgess J (2014) Twitter, brands, and user engagement. In: Weller K, Bruns A, Burgess J, et al. (eds) Twitter and Society. New York: Peter Lang, pp. 293-304.

Oktay JS (2012) Grounded Theory. New York: Oxford University Press.

Papacharissi Z (ed.) (2010) A Networked Self: Identity, Community and Culture on Social Network Sites. New York: Routledge.

Pew Research Center (2014) Key indicators in media \& news. Available at: http://www.journalism.org/2014/03/26/state-of-the-news-media-2014-key-indicators-in-media-and-news/

Phillips A (2010) Transparency and the new ethics of journalism. Journalism Practice 4(3): 373-382.

Revers M (2014) The Twitterization of news making: Transparency and journalistic professionalism. Journal of Communication 64(5): 806-826.

Robinson S (2011) Journalism as process: The organizational implications of participatory online news. Journalism Communication Monographs 13(3): 138-210.

Rosen J (2006) The people formerly known as the audience. Available at: http://archive.pressthink.org/2006/06/27/ppl_frmr.html

Rosen J (2010) The view from nowhere: Questions and answers. Available at: http://pressthink. org/2010/11/the-view-from-nowhere-questions-and-answers/ (accessed 13 January 2014).

Schultz B and Sheffer ML (2012) Personal branding still in future for most newspaper reporters. Newspaper Research Journal 33(4): 63-77.

Secko DM, Amend E and Friday T (2013) Four models of science journalism: A synthesis and practical assessment. Journalism Practice 7(1): 62-80.

Singer JB (2005) The political j-blogger: 'Normalizing' a new media form to fit old norms and practices. Journalism 6(2): 173-198.

Siraj-Blatchford I (1993) Educational research and reform - Some implications for the professional identity of early years teachers. British Journal of Educational Studies 41(4): 393-408.

Strauss AC and Corbin JM (1998) Basics of Qualitative Research: Techniques and Procedures for Developing Grounded Theory, 2nd edn. Thousand Oaks, CA: SAGE.

Turri AM, Smith KH and Kemp E (2013) Developing affective brand commitment through social media. Journal of Electronic Commerce Research 14: 201-214.

Tuten T and Solomon M (2012) Social Media Marketing. New York: Prentice Hall.

Williams J (2012) The basics of branding. Entrepreneur. Available at: http://www.entrepreneur. com/article/77408 (accessed 1 November 2013).

\section{Author biographies}

Avery E Holton (PhD, University of Texas at Austin, 2013) is an Assistant Professor and H2 Honors Professor in the Department of Communication at The University of Utah. His research emphasizes the intersections between digital and social media, mass media, and health and disabilities issues, and his work has appeared in Mass Communication \& Society, Communication Theory, Health Communication, Journalism Studies, Digital Journalism, and Journalism \& Mass Communication Quarterly, among others.

Logan Molyneux (PhD, University of Texas at Austin, 2015) is an Assistant Professor in Temple University's Department of Journalism. His research focuses on digital media and mobile technology, specifically as they relate to journalistic practices and products. His work has appeared in the Journal of Communication, Journalism Studies, and International Journal of Press/Politics, among others. 